\title{
Sustainable Use of Technology in Teaching: A Principled Approach
}

\author{
Talip Karanfil \\ Middle East Technical Universaity \\ Northern Cyprus Campus \\ E-mail: karanfil@metu.edu.tr \\ Steve Neufeld (Corresponding author) \\ Middle East Technical Universaity \\ Northern Cyprus Campus \\ E-mail: steve@metu.edu.tr
}

Doi:10.7575/aiac.alls.v.5n.5p.64

URL: http://dx.doi.org/10.7575/aiac.alls.v.5n.5p.64
Received: 18/06/2014

Accepted: 15/08/2014

\begin{abstract}
The bewildering pace of change in technology has had a polarizing effect on the teaching profession. Teachers tend to cope in two ways, either by finding the least invasive ways to use technology without interfering with their standard mode of practice, or by embracing technology at every step and turn in new and innovative ways. The former does a disservice to students, but the latter is unsustainable. This research explores the sustainability of using technology in teaching and puts forward principles and guidelines to determine the most effective technology to use in the most sustainable fashion. In this framework, the onus is put on students to complete active learning projects in and outside the classroom. The resulting learning environment and the learning activities employed in the classroom are investigated in this study. Data were collected via field notes, student interviews, researcher journal entries, and student reflections. The findings of this research indicate that a principled approach to the sustainable use of technology in teaching fosters a student-centered orientation which raises student motivation, reduces the affective filter and builds confidence without placing undue pressure on the teacher or on limited educational resources.
\end{abstract}

Keywords: sustainable CALL, technology and teaching, digital literacies

\section{Introduction}

Technology and teaching have been uneasy bedfellows from the very beginning (Thornburg, 1992). In the 17th Century, the preferred technology was the individual slate board. It wasn't until 1801, when the blackboard was invented, that technology changed the face of education from small classes with individualized instruction to "mass education". With the dominance of the blackboard technology as the primary information delivery system, students required a system to record notes using the newly emerging technology of paper and pencil. Of course, not everyone was happy with this change.

"Students today depend upon paper too much. They don't know how to write on slate without chalk dust all over themselves. They can't clean a slate properly. What will they do when they run out of paper?" Principal's Association, 1815

But the advances in technology continued, with the lead-based pencil giving way to pen and ink. While the medium of paper seemed to have become accepted, there were critics of the revolutionary emerging 'ink-based' technology.

"Students today depend too much upon ink. They don't know how to use a pen knife to sharpen a pencil. Pen and ink will never replace the pencil." National Association of Teachers, 1907

After over two centuries at the heart of every classroom, the mighty blackboard was threatened by the 'dry erase board' - most commonly known as the "whiteboard'. While it took less than two decades for the "dry erase board" to usurp the two-century dominance of the blackboard, such is the pace of technological change that the reign of the 'whiteboard' will be much shorter than its predecessor, with the 'smart board' becoming more and more commonplace in classrooms. And, of course, today the computer and data projector have also become a common feature in the classroom. And, like any new appearance of technology, this is not without its critics.

'The computer will take over everywhere from the operation of thinking, leaving the brain to lie fallow, as the mechanistic technologies of the nineteenth century have already done with the body. People are becoming increasingly zombie-like. It looks as if their brains have been removed and they are merely functioning on their spinal cords.' (Browne, 1996)

As with all previous innovations, computers in education eventually became commonplace. It seems ironic that the ultimate classroom technology may in the near future revert back to the 'one tablet per student' that characterized the technology of the classroom in the 17 th century, albeit the tablets are personal computers not slabs of stone (Chandler \& Tsukayama, 2014). 
This continual and unrelenting onslaught of new and unimaginable marvels of technology challenges teachers to keep up with an ever escalating rapid pace of development. One wonders how teachers will be able to effectively and sustainably exploit wave after wave of technological advances they encounter. Obviously, as seen by the historic debates over the choice of pen or pencil, blackboard or whiteboard, computer or tablet--the challenge to successfully exploit technology is not related to the technology itself, but rather in finding a principled and pedagogically sound approach to follow in using whatever new technology may appear for teaching and learning.

We hope to explore this idea that a set of pedagogically sound principles can provide a foundation on which teachers can effectively manage any technological innovation to maximize learning and inform better teaching practice. This seems particularly relevant today, when one reflects on the fact that technology throughout the past two hundred years has promised much, but has failed to live up to its true potential. In a recent survey of schools in the state of California, Larry Cuban (2009) found that there was no significant difference in the actual performance of students in classes that had used computers and advanced technology to the students who were schooled in traditional non-technology classrooms. Cuban did not find fault in the technology, but rather it was the lack of professional development for teachers to effectively integrate the technology with teaching that was the root of the problem, so that "the overwhelming majority of teachers employed the technology to sustain existing patterns of teaching rather than innovate." In other words, teachers generally lack the pedagogical principles to find novel ways to integrate new technology into their teaching practice.

\subsection{The realms of digital literacy - from resident to visitor}

As seen by the reactions of the educational establishment to new technologies over the past two centuries, one of the challenges is addressing the generational 'lag time' differential of adopting new technology between teachers and their students. With the increasing pace of technological change, this 'lag time' is becoming more and more obvious, none more so than the use of computers in education. Prensky coined the terms "Digital Natives and Digital Immigrants" in 2001 to exemplify the perceived gulf created by technology between students-the 'natives' and their teachers-the 'immigrants'. He postulated that today's students think differently because of their exposure to technology, creating a gap between their new way of learning and the traditional way of teaching of the older generation of teachers. A decade on and this polarization of two extremes is far from reality. White and le Cornu (2011) argue that it isn't age or skills that matters, but rather that there is a continuum in which people behave differently when using technology, depending on their motivation and context. In terms of our teaching context, this is a much more accurate way to describe the intent and use of technology-there are those of us who 'visit' a current technology to get a job done, and then there are those who 'reside' in that virtual world to do everything. Following a principled approach to seek out the middle ground where both teachers and students can comfortably co-exist seems to be a key element to ensure technological integration is effective and sustainable.

Aside from the issue of acceptance of technology, as highlighted in the previous section, a principled approach must also take into consideration the range of literacies that each new wave of technology requires. As in the past, when some teachers took comfort in sharpening pencils with knives while students were au fait with pen and ink, each individual developed their own range of literacies relevant to the technological medium of the day. This is no less true today, in terms of the literacies required in the digital age. And like yesteryear, individuals today occupy different comfort zones according to their relationship with new and emerging technologies-either as a 'visitor' or as a 'resident'. White \& Connaway (2011) identified some key characteristics which distinguish a 'digital visitor' and a 'digital resident'. In many cases, people can find themselves on a continuum somewhere between a 'resident' in some aspects of technology and a 'visitor' in others.

\begin{tabular}{|c|c|}
\hline Digital visitor & Digital resident \\
\hline $\begin{array}{c}\text { Unseen } \\
\text { Instrumental } \\
\text { Functional } \\
\text { Individual }\end{array}$ & $\begin{array}{c}\text { Visible } \\
\text { Networked } \\
\text { Communicative } \\
\text { Communal }\end{array}$ \\
\hline 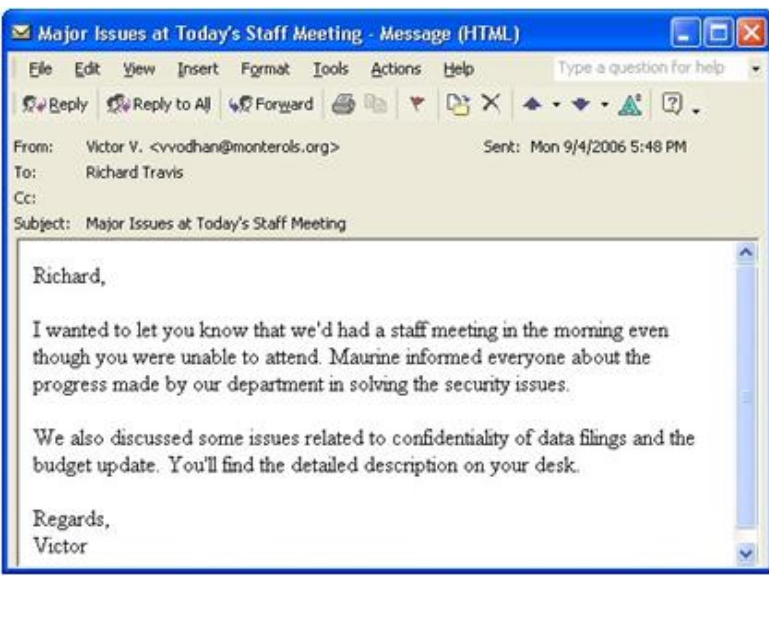 & 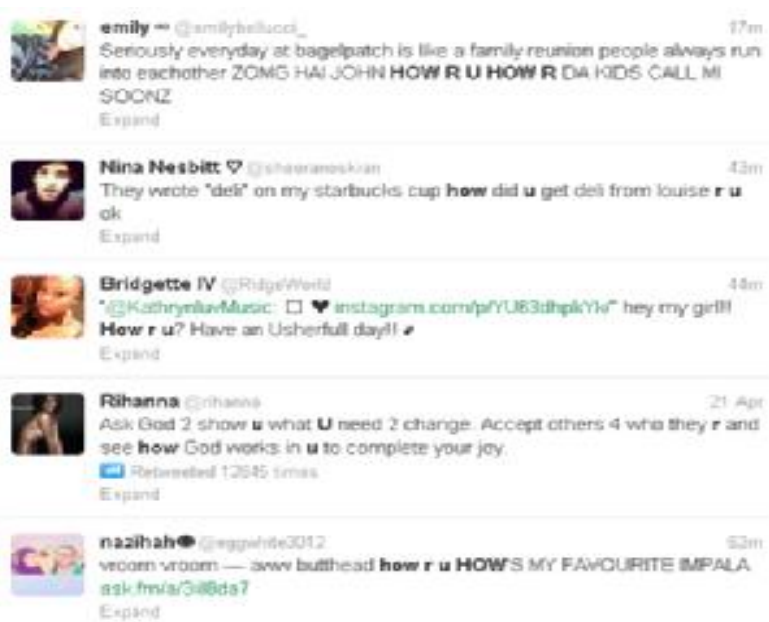 \\
\hline
\end{tabular}

Figure 1. Realms of digital residents and digital visitors 
The table above (fig.1) illustrates an extreme example of the difference between the realms of digital resident and visitor. The images contrast one aspect of the virtual world, computer mediated communication, with visitors tending to communicate by email, and being very effective in using that medium. Digital residents, on the other hand, rarely use email and communicate rather in short and continuous messaging, often in less than 140 characters at a time. When faced with the task of writing a formal email message, these digital residents would feel as uncomfortable and as illequipped as the digital visitors would feel if asked to put their lives in the public domain in a twitter stream.

Of course, residents and visitors don't exist entirely at opposite extremes. In fact, each of us has a mixed profile - in some cases we tend to digital residency, and in other cases we favour digital visitor status. Our status as a resident or visitor may change according to the context - personal or institutional. The realm of residency may vary, for example, young people define their residency using social media. Within social media, they can move effortlessly and adapt easily to different applications. However, when taken out of that realm, these social media residents can find themselves digital visitors in a world constrained by usernames and passwords in restricted virtual learning environments such as http://moodle.org, in which the teacher resides. With ever emerging new applications and platforms, it is becoming easier to find a middle ground where both the teachers and students can co-exist and feel comfortable. Classroom management platforms, such as http://edmodo.com or http://classdojo.com, and common workspace providers, such as http://quizlet.com and http://pbworks.com can be given as just a few examples of hundreds on the Internet that allow both digital visitors and residents to co-habitate virtual realms, ranging from personal to institutional contexts.

Just to illustrate the complex nature of an individual's relationship to technology, figure 2 below gives an example to illustrate the personal resident/visitor profile of one of the authors, in which various technology mediated applications are plotted according to visitor/resident orientation and purpose of use ranging from personal to institutional.

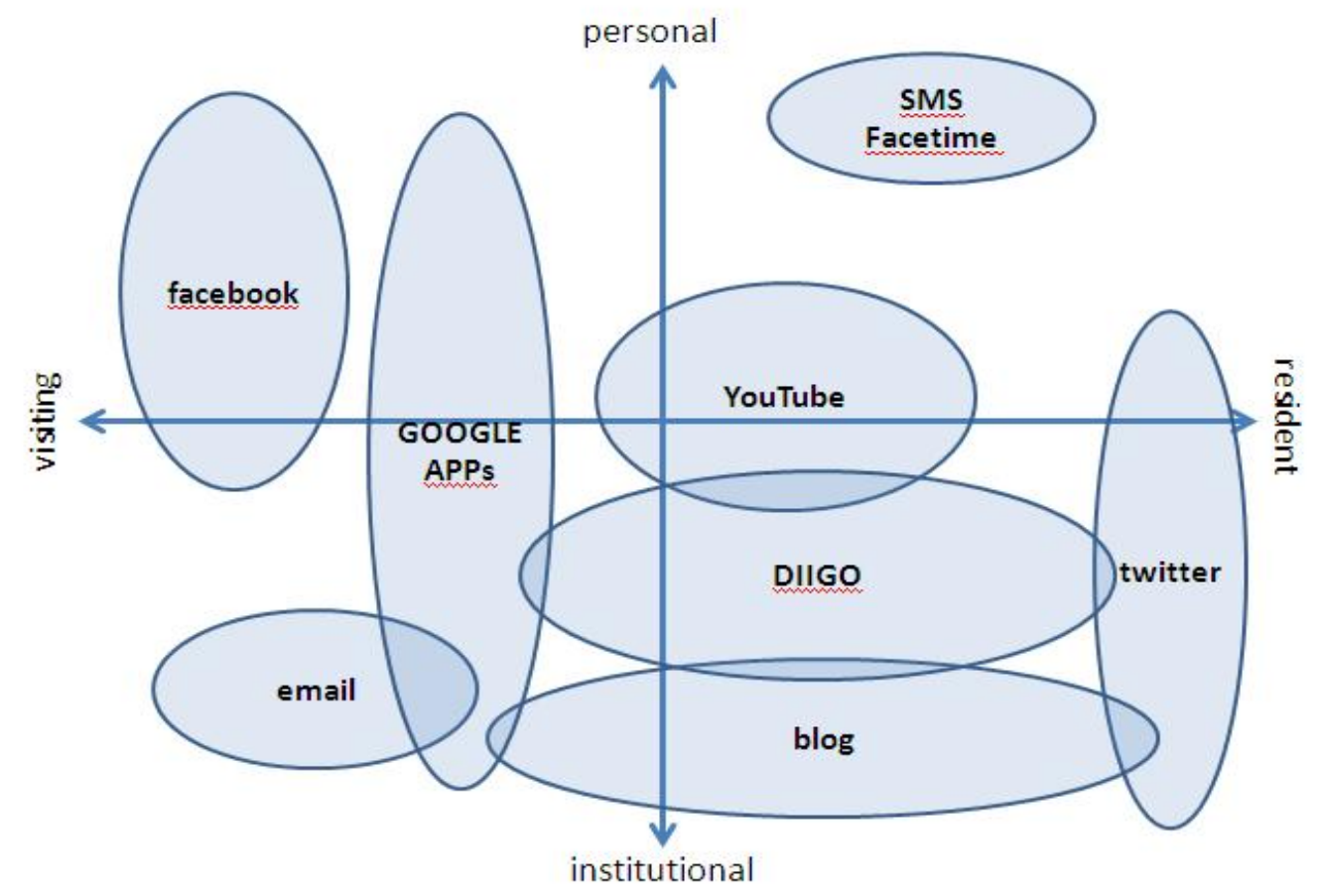

Figure 2. Individual digital resident/visitor profile

The term "blended learning" which Sharma (2010) has used to describe the integration of technology and teaching does not take into consideration the range and complexity of such personal resident/visitor profiles. Rather, it projects the idea that learning magically results when you put teachers, students, the curriculum, and technology together into one homogeneous mass. Instead, when it comes to integrating technology in education, the personal profiles of both teachers and students need to be considered, as well as the beliefs about the role technology plays in learning.

\subsection{Teachers beliefs and practices in using technology}

The defining challenge we face in the 21 st century is developing the ability to seamlessly weave established teaching principles with technology. In order to sustain this throughout their careers, teachers need to be able to learn from successive generations of 'tech-savvy' students, and become 'tech-comfy' enough to apply teaching principles within whatever technological paradigms they encounter. There are some fundamental obstacles to achieving this skill, the primary one being the fact that teachers are slow to transfer innovation into the classroom as Cuban (2009) found in his survey of teachers' practices. Egbert, Paulus and Nakamichi (2002, p. 111) support Cuban's findings, reporting that teachers generally find ways to fit technology into their standard practice rather than using technology as an opportunity to transform their teaching. Under certain conditions, however, teachers have been seen to adapt certain aspects of their classroom practice if the technology presents a solution to a problem that they perceive as important (Cuban, 1986, p. $70)$. 
We wanted to see if this trend is still prevalent in current teaching practice in our context, so we conducted an online survey of EFL instructors in North Cyprus in which 43 teachers responded and ranked their use of technologies in support of teaching. This snapshot of attitudes towards technology in teaching put word processing at the top, with Power Point presentations not far behind. The Internet and GOOGLE featured highly as well, suggesting that the focus is on preparing materials for input in class. In the chart below (fig.3), the red bars represent pre-Internet PC-based applications, and the dark blue represent the 'first generation' use of the Internet, where users are passive consumers of internet-based resources. The light green bars represent the 'second generation' of the Internet, often referred to as 'Web2.0', where users not only consume knowledge, but also generate and contribute content to the Internet. The light blue bars represent the communicative or social media elements of the Internet--the realm of the current generation of 'digital resident' students. Teachers, even those who are active users of the technologies of social media, especially instant messaging and even the mobile phone, rate this aspect of technology as being used very rarely in the context of teaching and learning. Obviously, when teachers are faced with choosing which technological platform to use as a pedagogical tool, they will lean to the realm in which they are 'resident', which is often the realm that students perhaps generally 'visit'. This mismatch may compromise the success of integrating technology in the learning process.

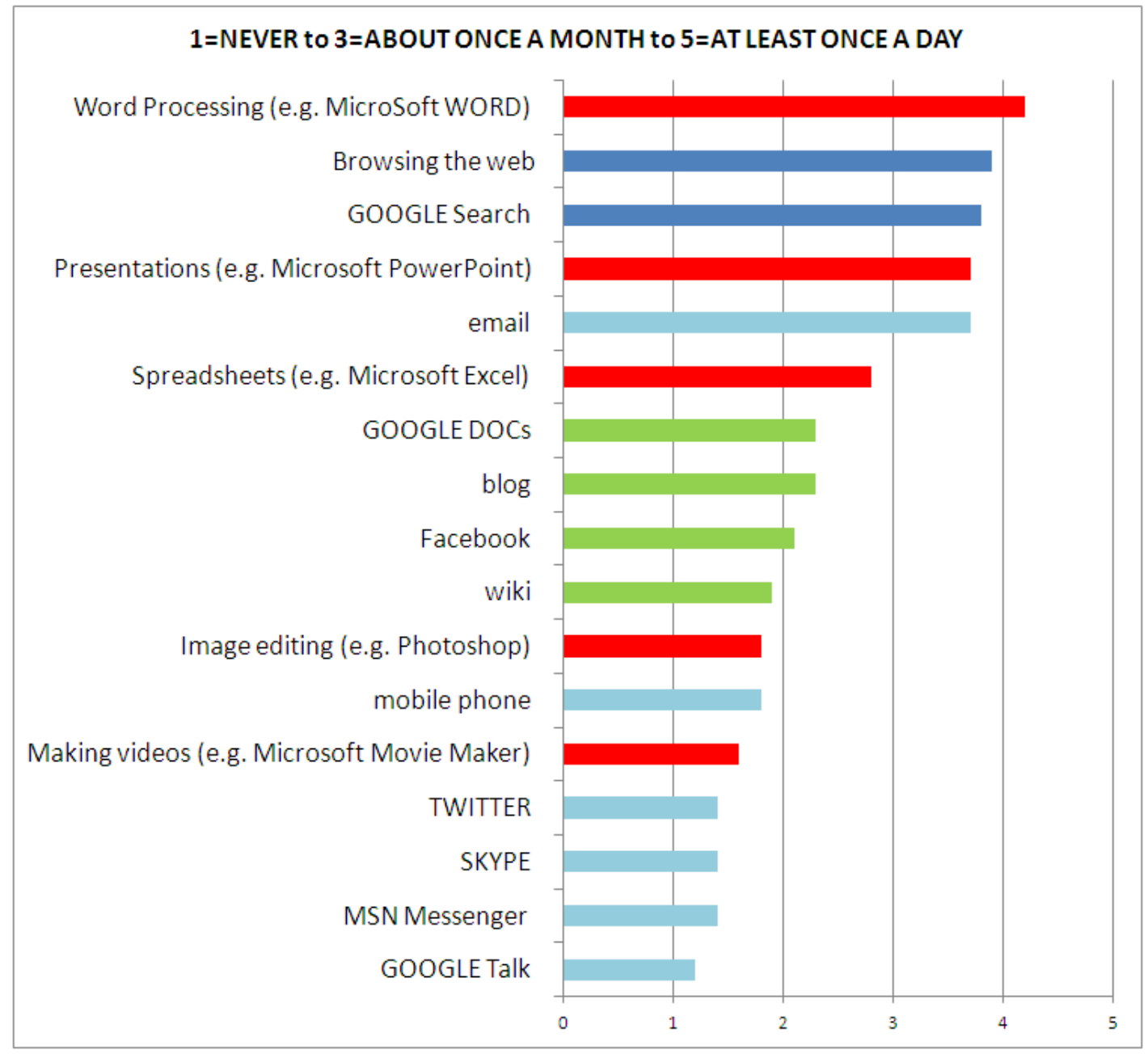

Figure 3. Attitudes towards technology and teaching as shown by frequency of use

\subsection{Beyond blended learning}

The research focus in this paper emerged from a need to study the parameters which foster the "education process" in a sustainable methodology using the technology available in the classroom and in consideration of the digital resident and visitor profiles of students and teachers. Sharma's widely accepted definition of blended learning (2010) focuses on the use of information technologies inside the classroom, leaving it primarily to the teacher to integrate the available technology into classroom teaching. In our case, typical of many English Preparatory Schools in North Cyprus and Turkey, the configuration of technology in the classroom includes a computer, a data projector and the Internet.

In terms of teaching practice, student involvement is often seen as the ultimate goal in order for language learning and teaching to be effective (Astin, 1999). Consequently, teachers and students need to be able to use information technologies according to their digital perspectives, resident or visitor, both inside and outside of class in a pedagogically sound manner which complements the main points in the syllabus. Of course, the degree to which students and teachers have autonomy to negotiate the prescribed course syllabus will vary according to the institutional context. Nevertheless, even within the strictest application of a lock-step syllabus there is the possibility to find room to maneuver. Indeed, regardless of technology, the pace of instruction must afford students some opportunity to work at 
their own pace according to their needs and ability, while at the same time contributing in the language education of their peers with the guidance of the teacher. Attempting to use the 'blended learning' approach to achieve this has not met with great success. As both Cuban (2009) and Egbert et al (2002) found, teachers have limited success in following a 'blended learning' model for the integration of technology, partly due to their tendency not to deviate from the status quo, but also for purely pragmatic reasons related to the sustainability of teaching practice within their limited resources of time and energy. Blended learning is like mixing olive oil and vinegar in a cup--it requires constant stirring to remain blended. In this analogy, the jar is the classroom, the olive oil represents the students, the vinegar is knowledge, and the spoon to stir the ingredients is technology. The energy to drive the stirring is provided by the teacher, who when exhausted must stop stirring, leaving the individual components to separate. Rather, as stated above, the main aim should be to provide a strong bound between these elements so that whatever is created during their synthesis stays intact as much and as long as possible, much like weaving different threads to create a tapestry. Each classroom experience is shaped by the interaction of students with their peers and their teacher, weaving the distinct threads of knowledge, students, technology, and the teacher in a unique and colourful tapestry. Unlike the oil and vinegar analogy, the woven experiences remain intact and provide the basis for a long-term learning and teaching experience. This weaving of technology with teaching and learning provides a foundation for the sustainable use of technology, which we have coined as 'woven teaching' to distinguish this methodology from 'blended learning'.

A recent technological thread that strengthens the sustainability of woven teaching is the use of mobile devices both in and out of class. This emerging technology, yet to be fully accepted in the classroom, means whatever is created in and out of class by the students and the teachers is available anytime, anywhere and generally free of charge. Mobile devices can facilitate group work, individual activities and pair work, allowing anything created in the classroom to be instantly available for everyone to share. Likewise, work outside the class can be shared and woven into the communal learning environment. Like all technology, its effectiveness and sustainability is dependent on the teacher making informed decisions based on pedagogically sound principles. A survey conducted in 2009 by Schachter revealed that over $70 \%$ of schools in the USA did not allow students to use mobile phones during the school day. Four years later, Dan Domenech, executive director of the American Association of School Administrators, (cited in Higgins, 2013) estimated that only $25 \%$ of schools allow mobile phones. The fact that so many schools and teachers ban the use of mobile phones in class suggests that, like the paper versus slate debate, teachers can only fall back on their traditional approaches to learning if they don't follow a principled approach to help them adjust and adapt to new and emerging technologies for educational purposes.

\subsection{A principled approach to sustainability}

In consideration of the background and issues relating to technology in education in the previous section, we formulated a set of principles to guide sustainable and effective use of technology in learning around five key factors: 1) acceptance of technology in general, 2) intent and use of technology in general teaching practice, 3) general teaching practices involving technology and specific innovations in language teaching, 4) the affective domain of teachers' beliefs and attitudes to technology, and 5) the time lag involved between visitors and residents of a technological paradigm.

A number of studies have put forward various models to determine if using technology is to be accepted as part of general practice. In 2013 Yucel and Gulbahar analyzed a review of the literature on the Technology Acceptance Model (Davis, 1989), and identified key variables that predict acceptance of technology in a wide range of fields (p. 103). In terms of an educational context, we took these variables into consideration when formulating a set of guiding principles in embracing technology as a sustainable and viable tool for innovation in teaching practice. Similar variables were identified by Cogus, Nistor, Riley, \& Lerche (2012) in their analysis of the Unified Theory of Acceptance and Use of Technology (Venkatesh, Morris, Davis \& Davis, 2003), in which the variables are classified in two groups-those which influence the intention to use technology and those that deal with the actual use of technology in teaching (p. 401). Together with the features of acceptance, we also considered the common teaching practices involving technology (Brown, 1999), technology and innovation in language teaching (Davies, 2005), the affective domain of teacher's beliefs and the 'lag time' between digital visitors and digital residents.

Following on from the findings of Cogus et al (2012), we developed two sets of principles-one to deal with the selection of the technology and the other relating to the use of technology in teaching and learning. The first set of principles is related more to effectiveness and the selection of appropriate technology to fit with intended outcomes, considering the resident/visitor profiles, the investment required in terms of time and money, and the potential to support long term goals and aims. The second set of principles relate more to the appropriate use of the selected technology in the learning process, making sure the technology fits seamlessly with the curriculum without extra course load burden or redundancy as well as providing opportunities for creativity and autonomy on behalf of both teachers and students. To make these principles as accessible to practitioners as possible, we focused on how to put the principles in action in a easy to understand framework. These two sets of principles that emerged from our research are summarized below.

The ACUTE principles guiding the selection of appropriate technology for maximum effectiveness can be briefly explained as follows.

- Acceptability - this principle questions whether the students accept to use the tool, platform or the software provided.

- Cost - Every educational endeavour, in this case the selected technology, should be analyzed in terms of its educational value for money.

- Usefulness - does it usefully augment learning? 
- Time - is it quick to learn, adapt and apply?

- Ease of use - is it easy to learn and use both for the teacher and the students?

Combined with these are principles related to the use of the selected technology in the classroom: the OFTEN principles of:

- Organization - how can the learners and language tasks in the curriculum be matched to the available technology?

- Facilitation - how can learners make use of technology to reinforce what they know, have learned and want to learn?

- Time - how to integrate technology to reach syllabus objectives within allocated instructional time?

- Expectations - what parameters need be set for effective use of technology while still allowing for experimentation and empowering student to take control and create?

- Novelty - how can we get students to go beyond the initial activity and suggest their own ways of exploiting their creations?

\subsection{Research questions}

Arising out of the need to find a framework for sustainable use of technology outside the conventional boundaries dictated by the concept of blended learning, we wanted to explore how well the ACUTE and OFTEN principles could be applied in a teaching context, and whether the resulting 'woven teaching' experience would:

1. promote a more student centered learning.

2. lower the affective filter and increase motivation to learn English.

3. provide a teaching protocol that could be sustainable within our ever increasing demands and workload.

\section{Methodology}

This study initially started with an English Preparatory School class of 23 'beginner level' students. The initial data was gathered during the 2011-2012 academic year, but since we followed an action research model (Burns, 2010) we have continued to apply ACUTE and OFTEN principles to test their sustainability with new and emerging technologies.

ACUTE and OFTEN principles form the basis for a framework to weave the old with the new to maximize learning and teaching on both an individual and institutional level in a sustainable manner. Here are some examples of how we applied this principles to select and manage technology to drive learning and student activity in the 'woven teaching' classroom. Following the initial wave of using such woven education activities with students, examples described in detail below, we surveyed the students using an online survey (ref.link 1). In addition, we kept field notes, conducted selected student interviews, we met on a regular basis to reflect on progress, and we asked students to reflect on their experience at the end of the course.

\subsection{DESCRIPTIVE VIDEO}

In terms of ACUTE principles, this activity augmented learning very well, as the focus of the video was chosen by the students from the syllabus, including reformulating processes in writing skills, simulating dialogues and responses to situations, and revising functional language studied in the course book. Students worked in groups to create their own video using a 'Common Craft' style, animating various still pictures in a video with narration according to this this procedure (ref.link 2). They used their own mobile phones to video the animation and publish it directly to YouTube, so it was acceptable to their digital literacies, very easy to do, and it required no extra cost. In terms of OFTEN principles, this activity was sustainable and effective, particularly in terms of the creativity it allowed students to innovate and take control over the creative process while facilitating their exploration of the language points in the syllabus. Here is an example of a descriptive video created by students (ref.link 3). The group prepared questions based on their video that their peers could answer while watching the video. Here is another example of how to write a paragraph (ref.link 4). In class we observed that the activity was well received by the students as well as getting a good rating in terms of ACUTE and OFTEN principles, aside from the effective use of time it took to do, and sustainability in terms of the time required to fit in with the prescribed syllabus. However, this is balanced by the high novelty factor, usefulness and ease of use, which appeared to make the language focus much more meaningful and memorable to the students.

\begin{tabular}{|l|l|l|l|l|l|l|l|l|l|l|}
\hline Steps in the process & A & C & U & T & E & O & F & T & E & N \\
\hline - Sts pick a topic (from syllabus) & & & $\checkmark$ & & $\square$ & $\square$ & & & & $\checkmark$ \\
\hline$\bullet \quad$ Work in teams & & $\square$ & $\square$ & & $\square$ & $\square$ & $\square$ & & $\square$ & \\
\hline$\bullet \quad$ Shoot the video & $\checkmark$ & $\square$ & $\square$ & & $\square$ & & $\square$ & & $\square$ & $\square$ \\
\hline - Sts prepare questions for class & & $\square$ & $\square$ & & & & $\square$ & & $\square$ & $\square$ \\
\hline - Video published online. & $\checkmark$ & & $\square$ & & $\checkmark$ & & & $\checkmark$ & & $\square$ \\
\hline - Qs on paper/online & & & & $\square$ & $\square$ & & $\checkmark$ & & & $\checkmark$ \\
\hline
\end{tabular}


In this activity, common errors, which were identified in the correction and feedback given to writing tasks assigned by the teacher, were compiled as examples of the common errors specific to the class. These were then published by the teacher in an online platform. The common error quizzes were published as interactive web pages. Here is an example of common errors regarding future predictions.(ref.link 4) In terms of ACUTE and OFTEN principles, this activity scores well on all counts, aside from the extra effort required by the teacher to compile and publish the common errors. However, this is more than balanced by the time saved in having students test themselves by correcting the errors online, and the novelty of having the examples of errors originating from the members of the class.

\begin{tabular}{|l|l|l|l|l|l|l|l|l|l|l|}
\hline Steps in the process & A & C & U & T & E & O & F & T & E & N \\
\hline$\bullet \quad$ T collects \& records student errors & & & & & & $\square$ & & $\square$ & & \\
\hline$\bullet \quad$ Errors compiled \& published & & & $\checkmark$ & & & $\square$ & & $\square$ & & \\
\hline$\bullet \quad$ Published online (edmodo or moodle) & $\square$ & $\square$ & $\square$ & $\square$ & $\square$ & $\square$ & $\square$ & $\square$ & \\
\hline$\bullet \quad$ Sts view the sentences/phrases & & $\checkmark$ & & $\checkmark$ & & $\square$ & $\square$ & & $\square$ & $\square$ \\
\hline$\bullet \quad$ Sts correct their own errors online or on paper & & & & & & $\square$ & $\square$ & & $\square$ & $\square$ \\
\hline$\quad$ Material provided by the sts, T compiled & $\checkmark$ & & $\checkmark$ & & & & & & & $\square$ \\
\hline
\end{tabular}

\subsection{GO ANIMATE}

In this activity, students worked in groups to create a dialogue based on a language point in the course book. Each group took turns at the classroom computer to create an animation of their dialogue. In the process, they experimented with nuances of the text-to-speech engine to get correct pronunciations of the Turkish names of their characters. For example, 'Emre' had to be transcribed as "M-ray". The animations were published on YouTube. Each group produced a list of questions to be answered by the other students when watching their dialogue. Some groups converted their questions to an interactive web page which their peers could access outside of class. Here are a couple of examples where a GOANIMATE animation was combined with an interactive web page: Arranging a meeting (ref.link 5) and asking directions (ref.link 6). Some students preferred to act out role plays themselves, creating a video of the role play, publishing it on YouTube and integrating it into an interactive web page with questions to answer while listening. Here is an example of meeting new people (ref.link 7). In terms of ACUTE and OFTEN principles, this activity scores less overall than the other activities, and like descriptive videos, places a premium on time in terms of effective use, but the ability for students to use the videos on their own time for revision was more of a bonus in terms of integration into the syllabus. Again, the novelty and usefulness factors made the activity more meaningful and memorable for the students.

\begin{tabular}{|l|l|l|l|l|l|l|l|l|l|l|}
\hline Steps in the process & A & C & U & T & E & O & F & T & E & N \\
\hline $\begin{array}{l}\text { Sts pick a topic in groups/individually from the } \\
\text { program }\end{array}$ & & $\checkmark$ & & $\square$ & $\square$ & & & $\square$ & $\square$ \\
\hline$\bullet \quad$ Work on the assignment (free user animation) & $\square$ & $\square$ & & $\square$ & $\square$ & & & $\checkmark$ & & $\checkmark$ \\
\hline$\bullet \quad$ During work sts revise \& study related topic & & & $\checkmark$ & & & & $\checkmark$ & & & \\
\hline$\bullet \quad$ Work checked before published & & & & & & & & & $\checkmark$ & \\
\hline$\bullet \quad$ Presented in class & & & & & & $\square$ & $\square$ & & & \\
\hline$\bullet \quad$ Animation available for use \& revision & & & $\checkmark$ & & $\square$ & $\square$ & & $\checkmark$ & & $\checkmark$ \\
\hline
\end{tabular}

\subsection{FLASHCARDS}

In this activity, students are assigned a task of creating a set of 10 flashcards of vocabulary every week. They are free to choose the words they include, as long as the words come from the assigned readings and course book activities. These are published and shared online in http://quizlet.com and shared in a virtual class (ref.link 8) with the other students. Students can access the cards on their mobile devices with a free APP, allowing them to use the cards and modify them whenever necessary. See this flashcard set (ref.link 9) as an example of student generated flashcards. Here is an example of a larger set of flashcards (ref.link 10), combined from individual student stacks by the teacher into one set for revision, with the facility of playing various games with the flashcard data. In terms of ACUTE principles, the use of an online vocabulary flashcard site is very effective. Students find the online site easy to use and the mobile 
device APPs fits in well with their digital literacies. The site is free to use, and it can be used by students directly to support the specific words they need to learn in the syllabus. By sharing not only the data, but also the rights to edit and copy, it makes it very time efficient for teachers to monitor for correctness. This particular activity also fits well with the OFTEN principles, and in the long-term is very sustainable as students can build on stacks from peers and previous student work.

\begin{tabular}{|l|l|l|l|l|l|l|l|l|l|l|}
\hline Steps in the process & A & C & U & T & E & O & F & T & E & N \\
\hline - At the end of every week, students pick vocabulary & & & $\checkmark$ & & $\checkmark$ & & & & \\
\hline $\begin{array}{l}\text { items from the syllabus covered. } \\
\text { - Sts find definitions/ context/ synonyms/ antonyms etc } \\
\text { to use as clues in their flashcards. }\end{array}$ & $\checkmark$ & & $\checkmark$ & & & $\checkmark$ & & & \\
\hline$\quad$ Sts prepare their flashcard sets online (for that week) & $\square$ & $\square$ & & $\checkmark$ & $\square$ & & $\square$ & $\square$ & $\square$ & $\square$ \\
\hline $\begin{array}{l}\text { Sts share their set online and download in APPs on } \\
\text { mobile devices }\end{array}$ & $\checkmark$ & & & $\square$ & & $\square$ & $\square$ & & \\
\hline $\begin{array}{l}\text { The material can be checked \& combined by the } \\
\text { teacher }\end{array}$ & $\checkmark$ & & & $\checkmark$ & & & & & $\square$ & $\square$ \\
\hline $\begin{array}{l}\text { Hundreds of flashcards are ready to exploit in/out of } \\
\text { classroom }\end{array}$ & $\square$ & $\square$ & $\square$ & $\square$ & $\square$ & $\square$ & $\square$ & $\square$ & $\square$ & $\square$ \\
\hline
\end{tabular}

\section{Results}

After implementing a range of activities designed for the sustainable use of technology in teaching, we surveyed the 23 students who took part using an online survey (ref.link 11). Out of the entire class, we received responses from 15 of the students. A summary of the responses is given below, organized around the four main research questions.

\subsection{Student-centered orientation}

The natural tendency when using techniques to promote the sustainable use of technology is to 'flip' the classroom (Stunz, 2013), in which the bulk of the responsibility for learning is shifted to the students by giving them the opportunity to experiment and attempt not just to learn the content but to work towards mastering proficiency. In the sustainable use of technology activities, this tendency is manifested by the students' perception of usefulness (fig.4).

Figure 4

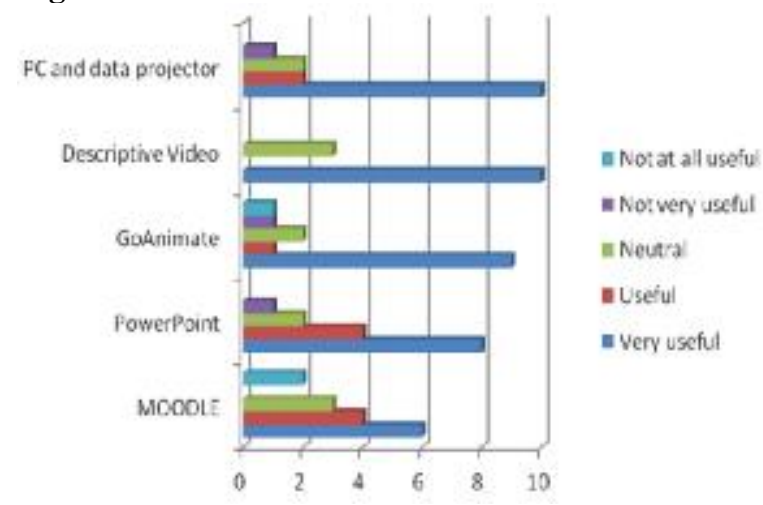

\section{Figure 5}

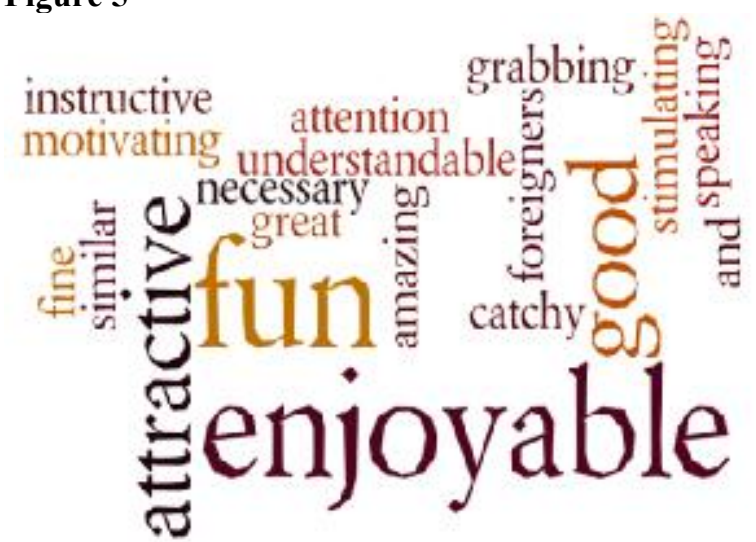

One of the questions in the survey asked students to use three adjectives to describe the technology assisted activities. The word cloud of adjectives used above (fig.5) shows the range of impressions that indicate the experience was viewed positively, with the larger words showing the more common.

\subsection{Motivation - student voices}

Since we were following an action research model, our students contributed to the flow and scope of the research. They were actively involved in using and managing the various online tools as well as participating in data collection. Apart from responding to a set of multiple choice questionnaire items, they were also asked to volunteer some personal comments. Here are the comments provided by the initial group of students, indicating an overall impression that students found the approach to be motivating. 
"We should have more activities like these to help us see that this is not a "lesson" to be passed from but it is a language we are trying to learn.”

"Use of variety of materials to attract students' attention without putting too much stress."

"The videos we watch, the e-mail we sent to space (ISS), the presentations we prepared depending on our own skills really helped us use the language in a meaningful way"

"One of the best ways of learning is that students should be at the center and produce something."

"I wish all classes were presented and studied via computer."

"Activities should be based on strengthening what is learned instead of trying to cover as many topics as possible."

"Descriptive videos, MOODLE, MPO can be useful."

"I think there should be more fun and catchy activities which allow more revision."

\subsection{Affective filter}

The students were asked to rate the range of teaching technique they were exposed to in class according to how these made them feel, from "Very Anxious" to "Relaxed". The responses (fig. 6 \& 7) indicate that woven teaching techniques to promote the sustainable use of technology tended to put students more at ease. From our observations in class, this breaking down of the affective filter seemed to boost the students' confidence and self-esteem. The students could be trusted to perform to the best of their ability, and they appeared more relaxed and able to experiment with the language through the activities, not as an end in itself. As a result, they seemed to develop more confidence in their own abilities and aptitude to learn.

\section{Figure 6}

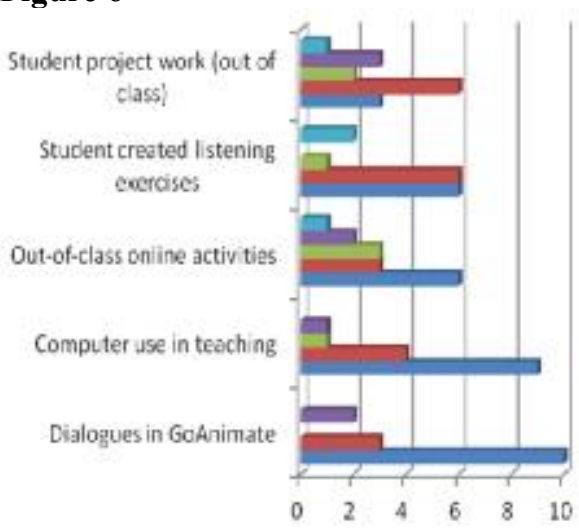

Figure 7

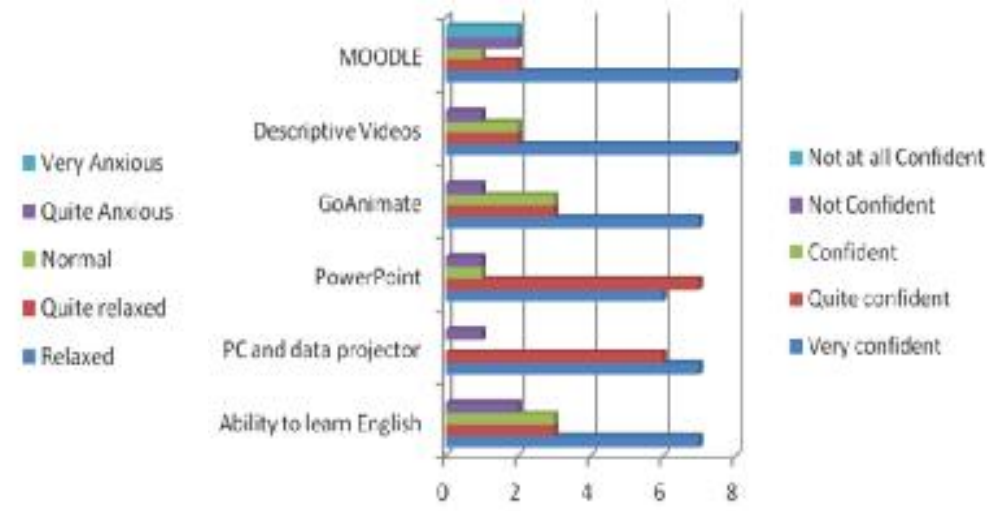

\subsection{Sustainability}

When this project first started, there were 23 students in one class. That class produced a number of materials of which we focus on vocabulary flash cards as an example. The instructors and students created about one hundred and fifty vocabulary flashcards. The material created was never deleted from the online site databases (studystack.com and quizlet.com). With every new semester, there was a new class and new students and new flashcards. Thus, in 2013-2014 Spring semester the number of those flash cards has reached more than 1000 when these flashcards are compiled together (ref link 13). While there is some duplication of target words, most clues and prompts are student-generated and provide a variety of contexts.

Content all created by students in the initial beginner group students--approximately

- $100+$ online exercises on Moodle

- $20+$ videos on YouTube

- 20+ listening recordings

- $150+$ vocabulary flashcards, with many more are added each subsequent semester

- All of these can be used with every new class, and accessed whenever or wherever appropriate

Having produced and compiled more materials during the following academic years (2012-2013 and 2013-2014 first semester), the numbers have risen. The effective use of smart phones has also had an effect on the creation of materials. Students are no longer confined to using computers. Thus, they can create and study their materials faster and whenever and wherever they want to. The same is true for the instructors as well. Some sample figures are given below: 
- $200+$ online exercises on Moodle + Edmodo (most activities have moved to Edmodo.com)

- $45+$ videos on YouTube + Edmodo + Vimeo (students have more options everyday)

- $40+$ listening recordings

- $1000+$ vocabulary flashcards

- More are added every week (since students use their smart phones more effectively, creating materials becomes easier)

\section{Discussion}

Based on our classroom experience, weaving technology in a sustainable fashion into the language learning program with regard to ACUTE and OFTEN principles injected much more meaning and energy into the teaching-learning interaction. The data gathered from students suggests that they found studying more meaningful since it was possible to engage in technology that they were already familiar with and make use of it throughout their studies. Furthermore, none of the students nor the instructors had to worry about any financial concerns since all of the platforms, websites and technology used throughout were free of charge. Of course, the availability of computer labs on campus and personal computers in the classroom helped a lot in implementing the desired plan.

We also mentioned that ACUTE and OFTEN principles can be applied to recent technological developments such as the all pervasive use of mobile devices and smart phones. A very basic example would be the use of flashcards. As mentioned above Quizlet and Studystack flashcard platforms have applications designed for mobile and smart phones. Thus, the students and the instructors are not confined to computers any longer. With the ever emerging technologies and with regard to increasingly sophisticated software developments, ACUTE and OFTEN can be applied to mobile technologies when trying to make use of such related technologies in language learning classes. Indeed, these principles can, to a large degree, ensure future-proofing in the face of the ever-increasing pace of change in technological innovation.

\section{Conclusion}

With respect to our research questions, the data and our observations in class clearly show that students felt more comfortable in learning experiences shaped by the ACUTE and OFTEN principles. It appears that the affective filter was lowered significantly since they were allowed to handle their learning through a medium they were already familiar and comfortable with, which in return enhanced learning (Lin, 2008). This is further supported by the comments that students volunteered, which show that woven teaching motivated the students and enhanced their learning experience in various ways.

Secondly, both students and the instructors were able to express themselves in terms of their language learning and teaching aims in various platforms, which added more variety into the classroom and the subjects. Conventional methods were backed up and enriched by the use of appropriate technologies. Another outcome supporting these principles above was that through the use of various computer or online based systems, work that was done either by the students or the instructors never drifted away from the main syllabus of the institution since both parties used these platforms in order to create 'artefacts' that were directly related to topics covered in the textbooks and in the syllabus of the institution. Student dialogue, critical thinking skills and creative thought processes were anchored in these concrete artefacts, which could be freely shared with peers and revisited thanks to the nature of the media used. Thus, while bringing variety into the program, these also created the possibility for revision. Moreover, due to the fact that all materials are in an electronic environment, these can be compiled and used in the future, which further supports the viability and sustainability of language learning technologies and materials.

Data collected from students suggests that woven teaching is a sustainable approach for using technology in teaching. The woven teaching guiding principles enable teachers to keep sight of objectives and intentions while coming to grips with each new wave of technological innovation. In order to select the most beneficial technology and technology-based resources, the principles of ACUTE and OFTEN provide an effective framework for any practitioner to follow. Woven teaching also reaps benefits in terms of reducing the affective barrier, and leads to a more student-centered approach which fosters higher motivation and active participation of students. Thus, these guiding principles do not just address the requirements of the institution or the demands of the instructor but they also accommodate an approach that attempts to take the students' needs and abilities into consideration.

\section{References}

Astin, A. W. (1999). Student involvement: A developmental theory for higher education. Journal of College Student Development, 40/5, 518-529.

Brown, K (ed). (1999). Using new technology in the classroom. New South Wales: Macquarie University: National Centre for English Language Teaching and Research.

Browne, L (1996). 'CALL and the negative view'. EA (ELICOS Association) Journal 14/1: 34-43, cited in Brown, K (ed). (1999). Using new technology in the classroom. New South Wales: Macquarie University: National Centre for English Language Teaching and Research.

Burns, A. (2010). Doing action research in English language teaching: A guide for practitioners. Routledge.

Chandler, M. \& Tsukayama, H. (2014). "Tablets proliferate in nation's classrooms, taking a swipe at the status quo." Washington Post 17 May 2014, sec. Education. Retrieved 17 May 2014 from http://www.washingtonpost.com/local/education/tablets-proliferate-in-nations-classrooms-and-take-a-swipe-at-thestatus-quo/2014/05/17/faa27ba4-dbbd-11e3-8009-71de85b9c527_story.html 
Cuban, L. 1986. Teachers and Machines: The Classroom Use of Technology Since 1920. New York: Teachers College Press.

Cuban, L. (2009). Oversold and underused: Computers in the classroom. Harvard University Press.

Davis, F. (1989). Perceived usefulness, perceived ease of use, and user acceptance of information technology. MIS Quarterly, 13, 319-340.

Davison, C. (2005). Information technology and innovation in language education (Vol. 1). Hong Kong University Press.

Egbert, J., Paulus, T.M. \& Nakamichi, Y. (2002). The impact of CALL instruction on classroom computer use: a foundation for rethinking technology in teacher education. Language Learning and Technology, 6/3: 108-26.

Gogus, A., Nistor, N., Riley, R. W., \& Lerche, T. (2012). Educational Technology Acceptance across Cultures: A Validation of the Unified Theory of Acceptance and Use of Technology in the Context of Turkish National Culture.Turkish Online Journal of Educational Technology-TOJET, 11(4), 394-408.

Higgins, J. (2013, August 7). More schools allowing students to bring smart phones, tablets to the classroom. USA Today. Retrieved July 15, 2014, from http://www.usatoday.com/story/tech/personal/2013/08/07/views-shift-on-cellphones-in-schools/2607381/

Lin, G. H. C. (2008). Pedagogies Proving Krashen's Theory of Affective Filter. Hwa Kang Journal of English Language \& Literature, 14: 113-131

Prensky, M. (2001). Digital Natives, Digital Immigrants Part 1. (R. K. Belew \& M. D. Vose, Eds.) On the Horizon, 9(5), 1-6. doi:10.1108/10748120110424816

Schachter, R. (2009). Mobile Devices in the Classroom. District Administration,45(10), 31.

Sharma, P. (2010). Key Concept in ELT; Blended Learning. ELT Journal, 64(4) doi:10/1093/elt/ccq043

Stuntz, D. F. (2013). Flipped classrooms and CALL sustainability: A rationale for the development of flipped classrooms for sustainable CALL. Glasgow, 10-13 July 2013 Papers, 323.

Thornburg, D. (1992). Edutrends 2010: Restructuring, Technology, and the Future of Education. San Carlos, CA: Starsong Publications

Venkatesh, V., Morris, M. G., Davis, G. B. \& Davis, F. D. (2003). User acceptance of information technology: Toward a unified view. MIS Quarterly, 27(3), 425-478.

White, D. S., \& Connaway, L. S. (2011). Digital visitors and residents: Project feedback. Oxford: University of Oxford. Retrieved from http://www.slideshare.net/jisc-elearning/digital-visitors-and-residents-project-feedback

White, D. S., \& Le Cornu, A. (2011). Visitors and Residents: A new typology for online engagement. First Monday, 16(9). doi:10.5210/fm.v16i9.3171

Yucel, U. A. \& Gulbahar, Y. (2013). Technology Acceptance Model: A Review of the Prior Predictors. Ankara University, Journal of Faculty of Educational Sciences, 46(1), 89-109.

\section{Reference Links Mentioned in the Text}

Reference link 1: online survey

https://docs.google.com/spreadsheet/viewform?usp=drive_web\&formkey=dEw4QXdSb2JwU3hLYXRxUHMzUEc1eH c6MQ\#gid=0

Reference link 2: this procedure http://sfltdu.blogspot.com/2012/01/descriptive-video-practiced-by-beginner.html

Reference link 3: descriptive video created by students http://youtu.be/51xPdMNIhJg

Reference link 4: how to write a paragraph

http://www.youtube.com/watch?v=OFzGP5s3dVs\&feature=share\&list=UUPy_1_Gsbv8aEq8IsyuXPIw

Reference link 5: common errors regarding future predictions

http://app.ncc.metu.edu.tr/sfl/mod/hotpot/view.php?id=261

Reference link 6: Arranging a meeting http://app.ncc.metu.edu.tr/sfl/mod/hotpot/view.php?id=196

Reference link 7: asking directions http://app.ncc.metu.edu.tr/sfl/mod/hotpot/view.php?id=225

Reference link 8: meeting new people http://app.ncc.metu.edu.tr/sfl/mod/hotpot/view.php?id=222

Reference link 9: virtual class http://quizlet.com/class/960421/

Reference link 10: flashcard set http://quizlet.com/37640012/second-vocabulary-list-flash-cards/

Reference link 11: larger set of flashcards http://www.studystack.com/flashcards-1444465

Reference link 12: online survey

https://docs.google.com/spreadsheet/viewform?usp=drive_web\&formkey=dEw4QXdSb2JwU3hLYXRxUHMzUEc1eH c6MQ\#gid=0

Reference link 13: compiled together http://www.studystack.com/flashcards-1444465 